\title{
Pengaruh Lintasan Combine Harvester Terhadap Pemadatan Tanah Saat Beroperasi
}

\section{(Effect of Combine Harvester Paths on Soil Compaction when Operating)}

\author{
Darmawati $^{\left.1^{*}\right)}$, Suhardi ${ }^{2)}$ dan Muhammad Tahir Sapsal ${ }^{3)}$ \\ ${ }^{1)}$ Program Studi Keteknikan Pertanian Universitas Hasanuddin \\ 2) Program Studi Keteknikan Pertanian Universitas Hasanuddin \\ 3) Program Studi Keteknikan Pertanian Universitas Hasanuddin \\ ${ }^{*}$ Email korespondensi: darmawati32@gmail.com
}

\begin{abstract}
ABSTRAK
Combine harvester sebagai alat panen sudah digunakan sampai saat ini, namun penggunaan alat ini hanya difokuskan kepada kinerja produktivitasnya. Sementara dampak penggunaan alat combine harvester yang dapat menimbulkan kerusakan tanah seperti pemadatan tanah kurang diperhatikan. Maka dari itu perlu dilakukan penelitian terhadap pengujian combine harvester untuk mengetahui pengaruh lintasan combine harvester terhadap pemadatan tanah saat beroperasi. Metode yang digunakan adalah dengan mengambil sampel tanah sebelum dan sesudah lintasan pada saat pemanenan untuk menganalisis nilai kadar air, bulk density, partikel density dan porositas guna melihat pengaruh lintasan combine harvester terhadap pemadatan tanah pada saat beroperasi. Berdasarkan hasil penelitian yang didapatkan maka dapat disimpulkan bahwa dari ketiga sampel perlakuan lintasan combine harvester pada saat beroperasi mengakibatkan nilai kadar air dan nilai porositas menurun sehingga nilai bulk density setiap sampel bertambah akibat dari tekanan combine harvester.
\end{abstract}

Kata Kunci: Combine Harvester, Pemadatan Tanah, Bulk Density

\section{PENDAHULUAN}

\section{Latar Belakang}

Pemanenan merupakan tahap pengelolaan dengan cara pemungutan menggunakan alat menual ataupun menggunakan reaper moderen dilanjutkan dengan perontokan dan pengemasan menggunakan karung. Penggunaan teknologi pertanian sangat mendukung kegiatan pada saat pemanenan, dimana saat panen dibutuhkan tenaga pekerja yang banyak agar pemanenan bisa dilaksanakan tepat waktu. Keperluan tenaga kerja yang sangat banyak pada saat panen ini menjadi persoalan karena semakin kurangnya tenaga kerja di sektor pertanian.

Data Badan Pusat Statistik (2014), pada tahun 2010 terjadi penyerapan tenaga kerja di sektor pertanian yaitu sekitar 38,69 juta tenaga kerja atau sekitar 35,76\% dari total penyerapan tenaga kerja. Penyerapan tenaga kerja terjadi penurunan pada tahun 2014 yaitu 35,79 juta tenaga kerja atau $30,27 \%$. Combine harvester merupakan peralatan penen yang bisa mematahkan bulir padi menggugurkan dan membuat gabah menjadi bersih dengan waktu panen lebih cepat. Menurut Direktorat PPHTP (2017), bantuan combine harvester telah diberikan kepada poktan atau gapoktan oleh Kementerian Pertanian sejak tahun 2012, jumlah bantuan combine harvester sampai saat ini yaitu 13.315 unit. Jumlah ini akan terus meningkat, karena pada tahun 2017, Kementerian Pertanian telah mengalokasikan combine harvester sebanyak 3.984 unit untuk mendorong panen serentak dan memudahkan petani dalam proses panen. 
Mekanisasi pertanian dengan menggunakan combine harvester sebagai alat panen sudah digunakan sampai saat ini. Namun penggunaan alat ini hanya difokuskan kepada kinerja produktivitasnya, sementara dampak penggunaan alat combine harvester terhadap lingkungan kurang diperhatikan. Umumnya penggunaan alat ini dapat menimbulkan kerusakan tanah seperti terbukanya lapisan tanah dan tanah akan menjadi padat.

Menurut James dan Donald (1993), tanah menjadi padat disebabkan karena ukuran ban, tekanan dari ban dan ukuran ban. Beban yang ringan pada mesin hanya menyebabkan pemadatan di permukaan tanah, mesin seperti combine dan mesin pemupukan beratnya bisa mencapai lebih dari 30 ton dapat menyebabkan pemadatan yang lebih dalam yang tidak dapat diperbaiki dengan pengolahan tanah. Pembebanan dan ukuran ban menyebabkan pemadatan yang lebih dalam pada tanah basah dari pada tanah kering.

Berdasarkan uraian tersebut maka perlu dilakukan penelitian untuk mengetahui pengaruh lintasan combine harvester terhadap pemadatan tanah saat beroperasi, agar penggunaan alat ini dapat digunakan dengan maksimal.

\section{Tujuan dan Kegunaan}

Tujuan dari penelitian ini untuk mengetahui bagaimana pengaruh lintasan combine harvester terhadap pemadatan tanah saat beroperasi. Kegunaan dari penelitian ini sebagai acuan dan informasi mengenai pengaruh lintasan combine harvester terhadap pemadatan tanah.

\section{METODOLOGI PENELITIAN}

\section{Alat dan Bahan}

Alat yang digunakan pada penelitian ini adalah combine harvester DC 60 digunakan sebagai alat pada pengujian, ring sampel 24 buah digunakan untuk wadah sampel tanah utuh, mistar digunakan mengukur kedalaman pengambilan sampel, stopwatch digunakan untuk mengitung waktu yang digunakan pada saat melintas, patok digunakan sebagai penanda pengambilan sampel, timbangan berat badan digunakan untuk menimbang operator dan pengemudi, plastik gula digunakan untuk membungkus sampel tanah, dan linggis digunakan untuk menggali sampel tanah. Bahan yang digunakan pada penelitian ini yaitu sampel tanah.

\section{Metode Penelitian}

Penelitian ini dilakukan pada satu petakan sawah untuk pengoperasian combine harvester dan mengambil sampel tanah untuk mengetahui pengaruh lintasan combine harveter. Pengambilan sampel tanah untuk pengujian di Laboratorium dilakukan sebelum pengoperasian combine harvester dan sesudah pengoperasian combine harvester.

\section{Pengambilan data lapangan}

a. Melakukan survey lokasi penelitian untuk pengoperasian combine harvester dan mempersiapkan alat dan bahan yang digunakan.

b. Memberikan tanda pengambilan sampel tanah sebelum dan sesudah lintasan combine harvester

c. Mengambil sampel tanah ban kiri dan ban kanan sebelum pengaplikasian combine harvester, dengan kedalaman 0-10 cm dan 10-20 cm untuk menentukan tekstur tanah, kadar air tanah, bulk density, partikel density dan porositas.

d. Melakukan pengoperasian combine harvester untuk melihat pengaruh lintasan, dimana berat combine harvester 2,45 ton dan ditambah berat pengemudi dan 2 asisten yaitu $172 \mathrm{~kg}$, dengan luasan ban yang bersentuhan dengan tanah yaitu $400 \times 1.545 \mathrm{~mm}$ sehingga besar tekanan beban rata-rata $0,21 \mathrm{~kg} / \mathrm{cm}^{2}$.

e. Menghitung kecepatan yang digunakan pada saat melintas dengan menggunakan rumus:

$$
\operatorname{Kecepatan}(v)=\frac{(s)}{(t)}
$$

keterangan:

$$
\mathrm{v}=\text { kecepatan }(\mathrm{m} / \mathrm{s})
$$


$\mathrm{s}=\operatorname{jarak}(\mathrm{m})$

$\mathrm{t}=$ waktu $(\mathrm{s})$

f. Mengambil sampel tanah untuk ban kiri dan kanan setelah pengoperasian combine harvester dengan kedalaman $0-10 \mathrm{~cm}$ dan $10-20 \mathrm{~cm}$ untuk menentukan kadar air tanah, bulk density, partikel density dan porositas.

g. Pengolahan data untuk menentukan tekstur tanah, kadar air tanah, bulk density, partikel density dan porositas.

\section{Tekstur Tanah}

Langkah-langkah dalam penentuan tekstur tanah menggunakan metode Hydrometer yaitu:

1. Menimbang $20 \mathrm{~g}$ tanah kering udara, berukuran kurang dari $2 \mathrm{~mm}$

2. Masukkan tanah ke dalam botol tekstur dan ditambahkan $10 \mathrm{ml}$ calgon $4 \%$ dan aquades secukupnya

3. Mengocok tanah dengan mesin pengocok selama kurang lebih 10 menit

4. Menuangkan semua isinya ke dalam silinder sedimentasi sebanyak $1000 \mathrm{ml}$ kemudian memasang saringan dengan diameter lubang sebesar $0.05 \mathrm{~mm}$ dan botol tekstur dibesihkan dengan menggunakan botol semprot

5. Mencukupkan larutan suspensi dalam silinder sedimentasi dengan air aqaudes hingga $1000 \mathrm{ml}$

6. Pasir yang ada didalam saringan dipindahkan dalam cawan dengan menggunakan botol semprot, kemudian dimasukkan kedalam oven dengan suhu $105^{\circ} \mathrm{C}$ selama 24 jam. Setelah itu dimasukkan kedalam eksikator (udara bebas) dan ditimbang hingga berat pasir diketahui (dicatat sebagai c gram)

7. Masukkan pengocok kedalam silinder sedimentasi lalu diaduk naik turun selama 1 menit

8. Masukkan hydrometer kedalam suspensi dengan sangat hati-hati agar suspensi tidak banyak terganggu

9. Setelah beberapa detik, dibaca dan catat $\left(\mathrm{H}_{1}\right)$ pada hydrometer beserta suhunya $\left(\mathrm{t}_{1}\right)$, dengan hati-hati hydrometer dikeluarkan dari suspensi
10. Setelah menjelang 8 jam, hydrometer dimasukkan kembali untuk membaca $\mathrm{H}_{2}$ dan $\mathrm{t}_{2}$

11. Menghitung berat debu dan liat menggunakan persamaan di bawah ini: Berat debu dan liat:

Berat liat:

$$
\left[\frac{\mathrm{H} 1+0,3(\mathrm{t} 1-19,8)}{2}\right]-0,5
$$

$$
\left[\frac{\mathrm{H} 2+0,3(\mathrm{t} 2-19,8)}{2}\right]-0,5
$$

Berat debu:

\section{Berat $($ debu + liat $)$ - berat liat}

12. Menghitung persentase pasir, debu dan liat dengan persamaan

$$
\begin{gathered}
\% \text { Pasir }=\frac{c}{a+c} \times 100 \% \\
\% \text { Debu }=\frac{(a-b)}{a+c} \times 100 \% \\
\% \text { Liat }==\frac{b}{a+c} \times 100 \%
\end{gathered}
$$

13. Memasukkan nilai yang didapat ke dalam segitiga tekstur.

\section{Kadar air tanah}

Pengukuran kadar air tanah dilakukan dengan metode gravimetri, pengukuran ini dimulai dengan mengambil sampel tanah dari lapangan kemudian ditimbang untuk mendapatkan berat basah (Wa). Selanjutnya sampel tanah dimasukkan ke dalam oven pada suhu $105^{\circ} \mathrm{C}$ selama 24 jam. Kemudian ditimbang untuk mendapatkan berat kering $(\mathrm{Wb})$. Perhitungan kadar air dilakukan pada kedalaman

0-10 $\mathrm{cm}$ dan 10-20 cm.

Dimana:

$$
K A=\left(\frac{W a-W b}{W b}\right) \times 100 \%
$$

$$
\begin{aligned}
& \mathrm{KA}=\text { kadar air tanah }(\%) \\
& \mathrm{Wa}=\text { berat sampel tanah basah }(\mathrm{g}) \\
& \mathrm{Wb}=\text { berat sampel tanah kering }(\mathrm{g})
\end{aligned}
$$

\section{Bulk density tanah}

Bulk density atau bobot isi tanah dapat dihitung menggunakan metode ring sampel yaitu dengan mengambil satu sampel tanah pada setiap titik dengan kedalaman $0-10 \mathrm{~cm}$ $10-20 \mathrm{~cm}$. Kemudian dihitung dengan persamaan:

$$
B D=\frac{B k}{V t}
$$

Keterangan:

$\mathrm{BD}=$ bulk density $\left(\mathrm{g} / \mathrm{cm}^{3}\right)$ 
$\mathrm{Bk}=$ berat kering $(\mathrm{g})$

$\mathrm{Vt}=$ volume tanah $\left(\mathrm{cm}^{3}\right)$

\section{Partikel density}

Partikel density dapat dihitung dengan menggunakan metode ring sampel yaitu dengan mengambil sampel tanah hasil analisa bulk density sebanyak $20 \mathrm{~g}$ yang lolos ayakan, lalu memasukkan ke dalam gelas ukur $50 \mathrm{ml}$ lalu di isi air $30 \mathrm{ml}$ dan diaduk untuk menghomogenkan air (partikel). Perhitungan nilai partikel density dengan kedalaman 0-10 cm dan 10-20 cm, kemudian dihitung dengan persamaan:

Keterangan:

$$
P D=\frac{B k}{V p t}
$$

$\mathrm{PD}=$ partikel density $\left(\mathrm{g} / \mathrm{ml}^{3}\right)$

$\mathrm{Bk}=$ berat kering $(\mathrm{g})$

$\mathrm{Vpt}=$ volume partikel tanah $\left(\mathrm{ml}^{3}\right)$

Porositas

Porositas adalah total pori dalam tanah yaitu ruang dalam tanah yang ditempati oleh air dan udara yang dihitung menggunakan metode hitungan dengan persamaan:

$$
\text { Porositas }=\left(1-\frac{\mathrm{BD}}{\mathrm{PD}}\right) \times 100 \%
$$

Keterangan:

$\mathrm{P}=$ porositas $(\%)$

$\mathrm{BD}=$ bulk density $\left(\mathrm{g} / \mathrm{cm}^{3}\right)$

$\mathrm{PD}=$ pertikel density $\left(\mathrm{g} / \mathrm{cm}^{3}\right)$

\section{Pola pemanenan}

Pada penelitian ini pola pemanenan yang digunakan yaitu pola keliling tepi (Gambar. 3), karena pola ini yang cocok untuk lahan yang panjang dan sempit. Pola keliling tepi ini biasanya digunakan pada saat pengolahan lahan maupun pada saat pemanenan.

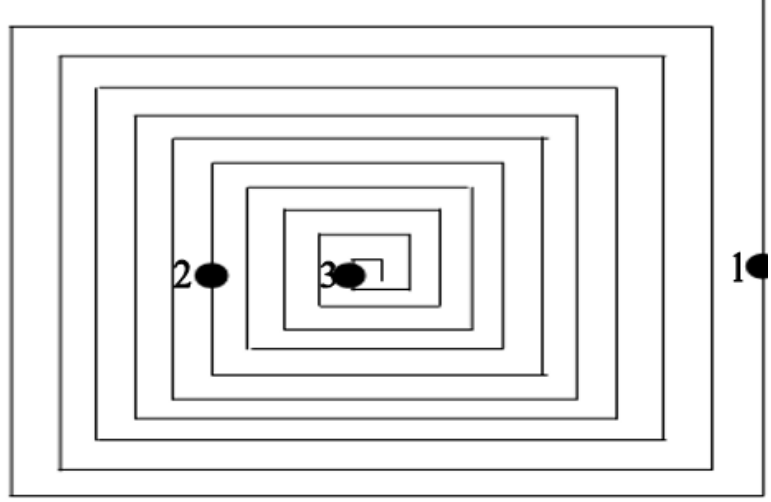

Gambar 1. Pola Keliling Tepi
Diagram Alir Penelitian

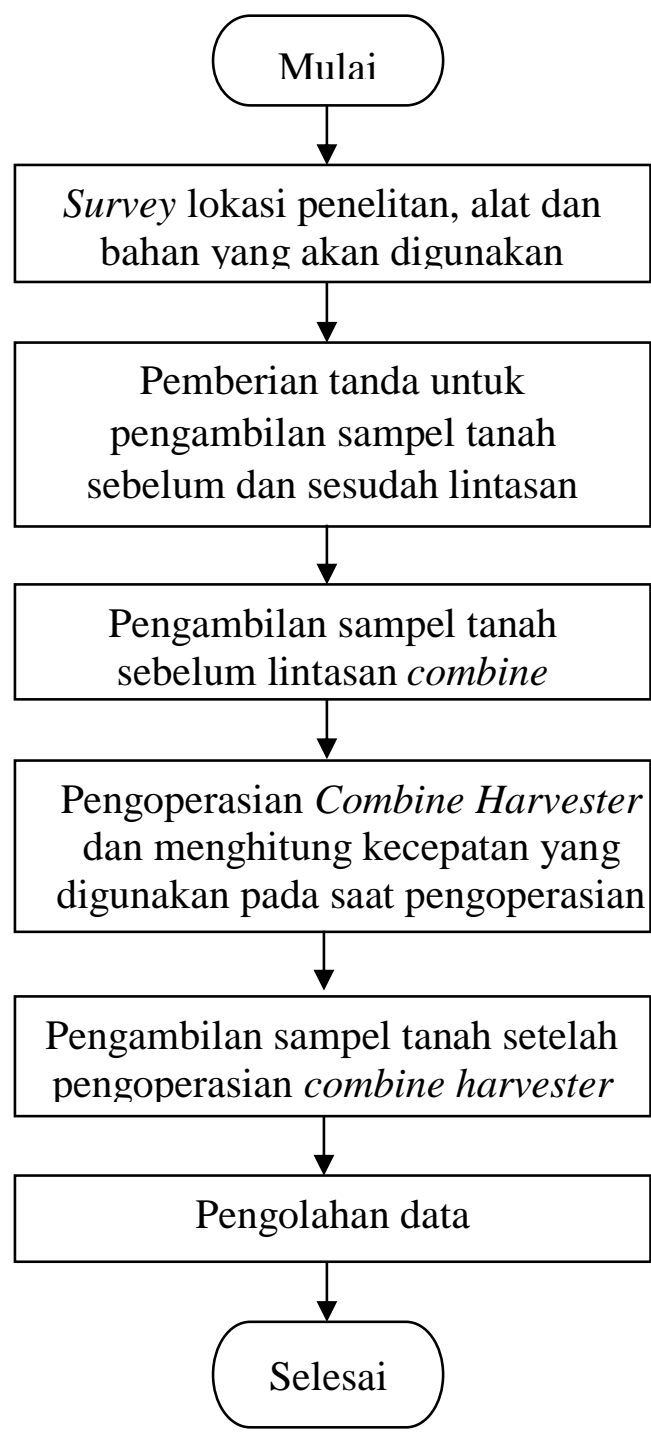

Gambar 2. Diagram Alir Penelitian.

\section{HASIL DAN PEMBAHASAN}

\section{Tekstur Tanah}

Keadaan tekstur tanah yang dijadikan sampel dalam penelitian ini yaitu bertekstur liat. Lahan ini merupakan lahan yang sebelumnya merupakan lahan untuk tanaman palawija. Peralihan fungsi lahan dari lahan untuk tanaman palawija ke lahan persawahan baru berlangsung selama 2 tahun. Berdasarkan hasil uji laboratorium tentang tekstur tanah pada setiap titik 
pengambilan sampel penelitian ini diperoleh tekstur seperti dibawah ini.

Tabel 1. Unsur Kandungan Tanah pada Areal Persawahan Tanaman Padi di Kabupaten Wajo

\begin{tabular}{|c|c|c|c|c|c|}
\hline \multirow{2}{*}{ No } & \multirow{2}{*}{ Sampel } & Pasir & Debu & Liat & \multirow{2}{*}{$\begin{array}{c}\text { Klas } \\
\text { Tekstur }\end{array}$} \\
\hline & & & $\%$ & & \\
\hline 1 & Sam! & 5 & 35 & 60 & Liat \\
\hline 2 & Sampel 2 & 9 & 38 & 53 & Liat \\
\hline 3 & Sampel 3 & 9 & 40 & 51 & Liat \\
\hline
\end{tabular}

Berdasarkan Tabel 1. dapat dilihat bahwa setiap titik pengambilan sampel mulai dari sampel 1 sampai dengan sampel 3 diperoleh kelas tekstur yaitu liat. Tekstur liat mempunyai karakteristik mengerut bila kering dan memiliki kemampuan menahan air yang baik. Sebagaimana pendapat Hardjowigeno (2010), yang menyatakan bahwa tanah-tanah bertekstur liat mempunyai luas permukaan lebih besar sehingga kemampuan menahan air dan menyediakan unsur hara yang tinggi.

\section{Pengaruh Tekanan Combine Harvester Terhadap Kadar Air}

Pengambilan sampel tanah dalam penelitian ini dilakukan pada dua kedalaman yakni $0-10 \mathrm{~cm}$ dan $10-20 \mathrm{~cm}$. Pada pengambilan sampel kedalaman 0-10 cm memiliki persentase kadar air lebih kecil dibandingkan sampel kedalaman 10-20 cm. Sampel 1 memiliki pesentase kadar air yang besar karena pengambilan sampel 1 berdekatan pada lubang pematang atau saluran untuk mengalirkan air dari petak sawah ke petak sawah lain, sampel 2 berada tidak jauh dari pengambilan sampel 3, dimana sampel 3 berada hampir di tengah sawah. Perbedaan pengambilan titik sampel tersebut berguna untuk melihat pengaruh lintasan terhadap beberapa titik dengan melihat pengaruh kadar air setelah dilintasi.

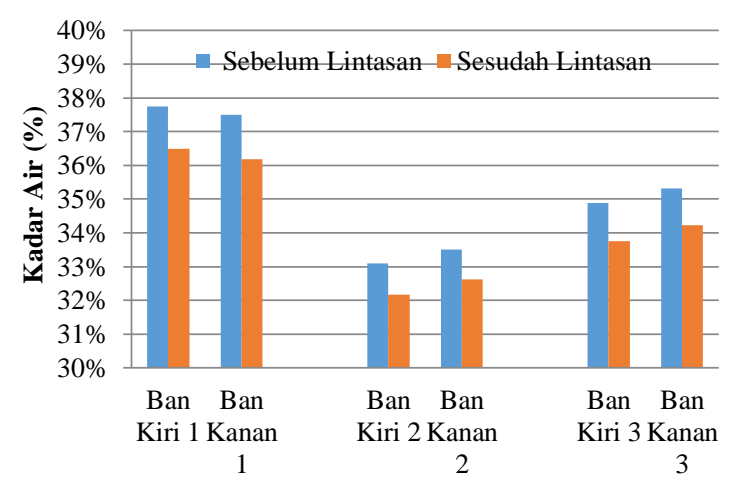

Gambar 3. Nilai Kadar Air pada Kedalaman 0-10 cm

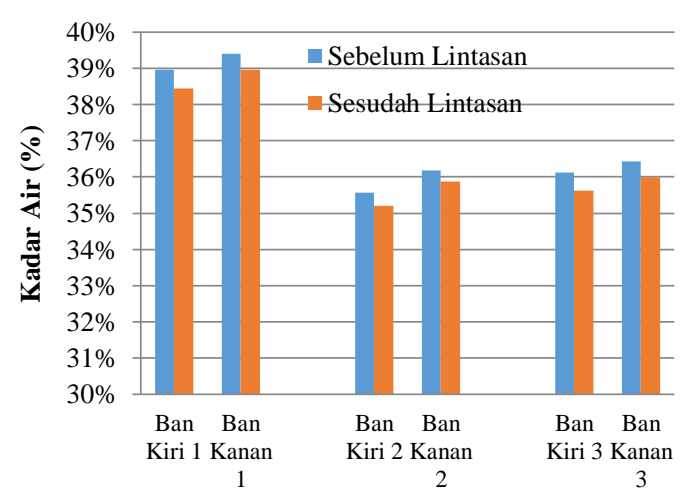

Gambar 4. Nilai Kadar Air pada Kedalaman 10-20 cm

Dapat dilihat dari gambar 3 dan 4 menunjukkan persentase penurunan kadar air setelah dilintasi combine harvester terjadi pada semua titik dan semua kedalaman. Hal ini disebebkan karena adaya tekanan combine harvester sehingga menyebabkan penurunan nilai persentase kadar air. Pada kedalaman 0-10 cm, setelah dilintasi combine harvester penurunan paling tinggi terjadi pada sampel 1 yaitu sebesar 3,32\% pada ban kiri dan 3,40\% pada ban kanan. Penurunan terendah diperoleh pada sampel 2 yakni sebesar $2.83 \%$ pada ban kiri dan 2,64\% pada ban kanan. Pada kedalaman 10-20 cm, penurunan kadar air tertinggi setelah dilintasi combine harvester diperoleh pada titik 1 yakni $1,32 \%$ pada ban kiri dan $1,15 \%$ pada ban kanan. Penurunan kadar air terendah diperoleh pada titik 2 yakni $1,03 \%$ pada ban kiri dan $0,85 \%$ ban kanan. Penurunan kadar air antara ban kiri dan ban kanan tidak jauh berbeda karena tekanan yang diperoleh relatif sama dan kadar air sebelum dilintasi combine harvester tidak jauh berbeda. 


\section{Pengaruh Tekanan Combine Harvester Terhadap Bulk Density}

Berdasarkan uji Laboratorium seperti pada gambar 5 dan 6 memperlihatkan bahwa dari ketiga sampel bulk density sebelum dilintasi combine harvester tidak jauh berbeda, tingginya nilai bulk density mempengaruhi kadar air. Hal ini sesuai pendapat Kurnia (2006), yang menyatakan bahwa pada tanah yang memiliki karakteristik mudah mengembang dan mengerut, maka nilai bulk density tanah berubah-ubah seiring dengan berubahnya kadar air tanah, sehingga untuk tanah yang mengembang dan mengerut, nilai bulk density perlu disertai dengan data kadar air

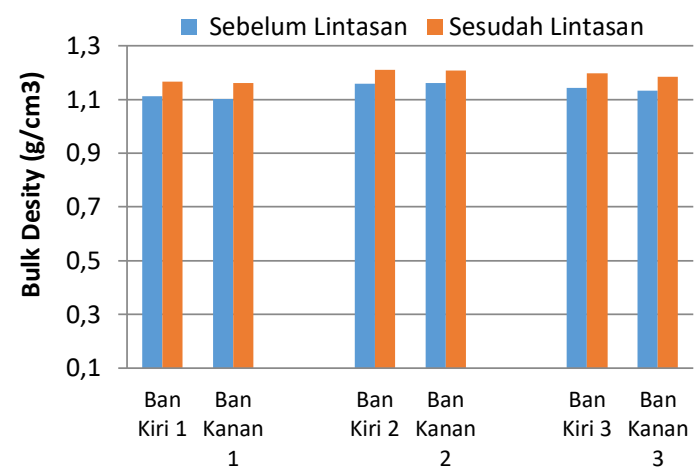

Gambar 5. Nilai Bulk Density pada

Kedalaman 0-10 cm

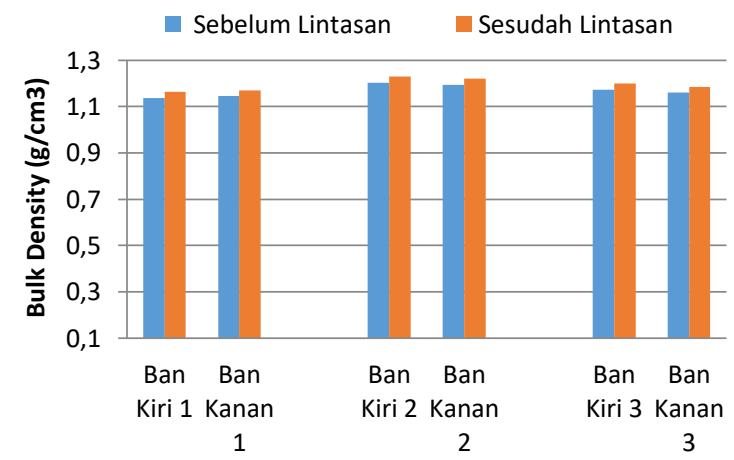

Gambar 6. Nilai Bulk Density pada

Kedalaman 10-20 cm

Perbedaan pengambilan titik sampel berguna untuk melihat pengaruh tekanan combine harvester terhadap beberapa titik pengambilan sampel. Pada penelitian ini pengaruh tekanan terhadap pemadatan tanah antara ban kiri dan ban kanan dari ketiga sampel tidak jauh berbeda, dimana besar tekanan beban rata-rata yang didapatkan $0,21 \mathrm{~kg} / \mathrm{cm}^{2}$. Perbedaan kenaikan bulk density ketiga sampel antara ban kiri dan kanan terjadi karena adanya perbedaan nilai persentase kadar air, dimana apabila bulk density tinggi maka kadar air akan rendah. Sehingga faktor yang mempengaruhi terjadinya perubahan nilai bulk density yaitu berat, tekanan dan kadar air.

Pengaruh peningkatan nilai bulk density dari ketiga sampel tersebut disebabkan karena berat combine harvester 2.62 ton, 1 kali lintasan dan kecepatan yang digunakan $1,28(\mathrm{~m} / \mathrm{s})$. Peningkatan nilai bulk density dari ketiga sampel setelah dilintasi combine harvester mengalami kenaikan namun tidak begitu besar, ini disebabkan karena pembebanan yang diberikan dari ketiga sampel tersebut sama. Hal ini sesuai pendapat Kasim (1992), yang menyatakan bahwa perubahan nilai bulk density tanah dapat dihasilkan oleh pembebanan dan intensitas lintasan. Kecenderungan kenaikan nilai bulk density seiring semakin tingginya intensitas lintasan disebabkan oleh tekanan yang berasal dari roda mendesak air dan udara sehingga poripori tanah semakin sempit dan tanah menjadi lebih padat dan secara tidak langsung meningkatkan nilai bulk density tanah.

Pengaruh lintasan combine harvester terhadap bulk density sangat terlihat pada daerah permukaan tanah yaitu pada kedalaman 0-10 cm. Gambar 5 memperlihatkan nilai ketiga sampel bulk density, dimana pada kedalaman 0-10 cm kenaikan bulk density tertinggi pada sampel 1 yaitu 5,06\% pada pada kiri dan pada ban kanan 5,24\% dan kenaikan bulk density terendah pada sampel 2 yaitu $4,47 \%$ pada ban kiri dan $4,15 \%$ pada ban kanan. Pada kedalaman 10-20 cm memperlihatkan kenaikan nilai bulk density tertinggi pada sampel 1 yaitu 2,43\% pada ban kiri dan 2,19\% pada ban kanan dan kenaikan bulk density terendah pada sampel 2 yaitu 2,09\% pada ban kiri dan 2,04\% pada ban kanan. Hal ini sesuai dengan penelitian iqbal (2006), yang menyatakan bahwa pengaruh intensitas lintasan pada kedalaman 10-20 cm masih 
terlihat pengaruhnya walaupun tidak sebesar pada kedalaman permukaan yaitu $0-10 \mathrm{~cm}$.

\section{Pengaruh Tekanan Combine Harvester Terhadap Porositas}

Pada penelitian ini diperoleh nilai persentase porositas sebelum dilintasi combine harvester besar, hal ini disebabkan karena porositas tanah sebelum dilintasi berukuran besar sehingga mengakibatkan air masuk kedalam tanah. Hasil analisis nilai persentase porositas sebelum dilintasi combine harvester tidak jauh berbeda, ini disebabkan karna nilai kadar air sebelum dilintasi tidak jauh berbeda.

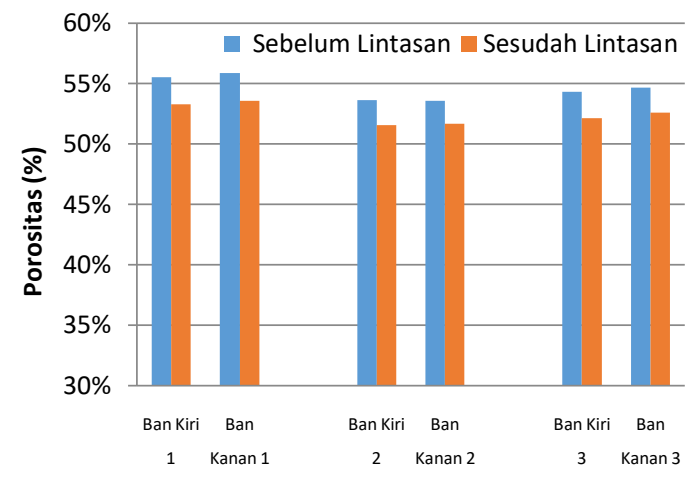

Gambar 7. Nilai Porositas pada Kedalaman 0-10 cm

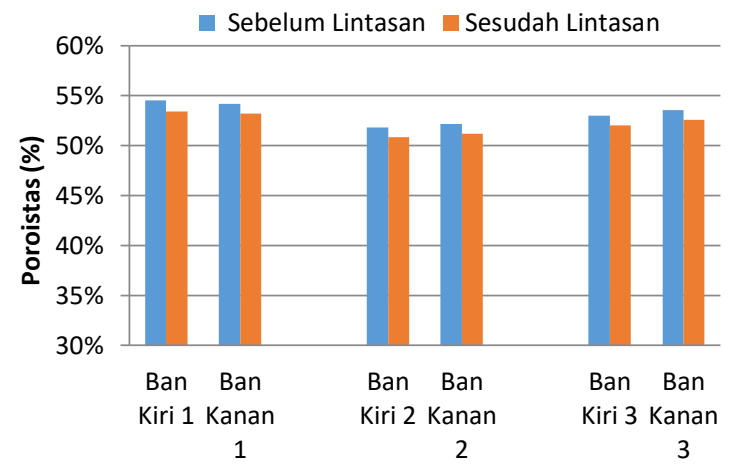

Gambar 8. Nilai Porositas pada Kedalaman 10-20cm

Penurunan porositas disebabkan karena adanya tekanan yang disebabkan oleh tekanan dari roda ban combine harvester, tekanan pada tanah ini akan menimbulkan penyempitan ruang pori tanah sehingga menurunkan nilai porositas. Hal ini sesuai pendapat Perdana (2015), yang menyatakan bahwa Pengaruh tekanan beban dari atas dapat menyababkan ruang total pori berkurang, sehingga terjadi proses pemadatan bahan penyusun tanah dan terjadilah pengurangan rongga udara didalam tanah. Terjadinya penurunan nilai total ruang pori didalam tanah maka akan menyebabkan peningkatan nilai bulk density didalam tanah

\section{KESIMPULAN}

Berdasarkan Penelitian yang telah dilakukan maka diperoleh kesimpulan sebagai berikut:

1. Pengaruh lintasan combine harvester terhadap pemadatan tanah menyebabkan kenaikan nilai bulk density serta persentase kadar air dan persentase porositas mengalami penurunan.

2. Peningkatan nilai bulk density setelah dilintasi combine harvester sangat terlihat pengaruhnya pada kedalaman 0$10 \mathrm{~cm}$ dibandingkan kedalaman 10-20 $\mathrm{cm}$.

\section{DAFTAR PUSTAKA}

Badan Pusat Statistik. 2014. Rencana Strategis Kementrian Pertanian Tahun 2015-2019. Badan Pusat Statistik: Jakarta.

Direktorat PPHTP. 2017. Combine Harvester: Solusi Untuk mengatasi Kelangkaan Tenaga Panen dan Evisiensi Biaya Usaha Tani. Ditjen Tanaman Pangan: Jakarta.

Hardjowigeno, S. 2010. Ilmu Tanah. PT Mediyatama Sarana Perkasa: Jakarta.

Iqbal, Tineke Mandang dan E.Namaken Sembiring. 2006. Pengaruh Lintasan Traktor dan Pemberian Bahan Organik Terhadap Pemadatan Tanah dan Keragaman Tanaman Kacang Tanah. Jurnal Keteknikan Pertanian: Bogor.

James, CF dan Donald LP. 1993. Soil Compaction: The Silent Thief. Publications of Departement of Agricultural Engineering the Missouri University: Columbia 
Kasim. 1992. Pengaruh Pembebanan dan Lintasan Roda Traktor terhadap Terjadinya Pemadatan Tananh dan Tanah Berliat. Institut Pertanian Bogor: Bogor.

Kurnia, Undang dkk. 2006. Sifat Fisik Tanah dan Metode Analisis. Balai Besar Litbang Sumberdaya Lahan Pertanian: Jakarta.

Perdana, Sandi dan Wawan. 2015. Pengaruh Pemadatan Tanah Gembut Terhadap Sifat Fisik pada Dua Lokasi yang Berbeda. Fakultas Pertanian: Riau. 